\title{
PLACENTAL HAEMOPHAGOUS ORGANS IN THE PROCYONIDAE AND MUSTELIDAE
}

\author{
R. F. S. CREED AND J. D. BIGGERS \\ Royal Veterinary College, London, N.W.1, and the King Ranch Laboratory of \\ Reproductive Physiology, School of Veterinary Medicine, University of Pennsylvania, \\ Philadelphia, U.S.A.
}

(Received 9th Fanuary 1964)

\begin{abstract}
Summary. A description is given of some of the gross anatomical characteristics of the placenta of representatives of five carnivore species of the families Procyonidae and Mustelidae. Emphasis is laid on the occurrence of well-defined haemophagocytic structures in these placentae, which have not, hitherto, been investigated.
\end{abstract}

\section{INTRODUCTION}

Recently, the name haemophagous organ was proposed for a particular structure found in the raccoon (Procyon lotor lotor L.) placenta (Biggers \& Creed, 1962). This highly vascular sac-like structure, which hangs into the allantoic cavity, is of macroscopic dimensions and emerges from a central antimesometrial region of the placental annulus in this procyonid carnivore (Pl. 1, Fig. 1). It increases in size and complexity until about two-thirds to three-quarters of the gestation period has elapsed, after which it regresses. Morphologically it is quite distinct from the rest of the placenta which is labyrinthine, and histological examination shows it to be made up of a series of branching and anastomosing lamellae which consist of a thin core of foetal mesenchyme, containing foetal capillaries, lined on either side by tall foetal columnar epithelial cells. Interlamellar spaces are filled with maternal blood which gains access from the maternal side at the base of the haemophagous organ, and bathes the foetal columnar epithelium. The cells of this epithelium bear every indication of being phagocytic and appear to be concerned essentially with the ingestion of maternal blood corpuscles (Biggers \& Creed, 1962; Creed \& Biggers, 1963a, b). The haemophagous organ may play a particular role in foetal exchange and the concept of its being a kind of extra-foetal digestive mechanism for complex substances has been tentatively advanced (Creed \& Biggers, 1963b). It is likely that the haemophagous organ is equivalent to the so-called 'haematoma' of the placentae of certain other carnivores and the suggestion has been made that the term 'haematoma' with its pathological implications might with advantage be discontinued and the more functional and descriptive term 'haemophagous' be applied to such haemophagocytic regions of the placenta (Creed \& Biggers, 1963b). 
More recently it has been possible to examine the placentae of members of five other carnivore species belonging to the families Procyonidae and Mustelidae. In none of these species has the placenta hitherto been the subject of any report, and in some of them it seems likely that it may never have been previously observed. Initial studies were directed with particular reference to the possibility of the existence of haemophagocytic regions and the following preliminary report is concerned with that aspect of the placenta. It is confined, with one exception, mainly to gross anatomical characteristics although histological confirmation of the structure has been made in each case.

\section{PROCYONIDAE}

Bassaricyon gabbi orinomus Goldman-the Olingo

In the case of this species, our somewhat brief observations resulted from the examination of a few transverse sections of the placenta. These were presented to us by $\mathrm{Dr} \mathrm{H}$. W. Mossman and were from an olingo which weighed $1.7 \mathrm{~kg}$ and had been obtained in 1949 in the Rio Cuango area, Palenque, Colon Province, Panama, by Dr W. A. Wimsatt. The sections had been cut through an early locular enlargement of the uterus and may have been taken out of a series. They are few in number but despite this they reveal the fact that the olingo placenta at this early stage does possess an haemophagous organ consisting of a large number of haemophagocytic cells arranged in epithelia. In the absence of observations on the gross anatomy of intact gravid uteri and because the available sections do not form a series, it is difficult to make positive assertions about the haemophagous organ in this species. There are indications, however, that it is in a central antimesometrial position as in the raccoon but that in contrast to its single lobed nature in that species, it may, in the olingo, be multilobular. Its extent and size at this stage cannot be assessed from the available material.

\section{MUSTELIDAE}

\section{Lutra canadensis-the Canadian river otter}

This specimen, fixed in $10 \%$ formalin, consisted of a single conceptus which had been removed from the gravid uterus of an otter captured in Western Montana on 15th March 1956. This had been obtained by Vernon Hawley and Kenneth Grier of the Montana Fish and Game Department and sent to us by Dr P. L. Wright. Information on the body weight of the animal and details of

\section{EXPLANATION OF PLATE 1}

$F=$ foetus; Ho $=$ haemophagous organ; $\mathbf{M}=$ mesometrium; $\mathbf{P A}=$ placental annulus Each figure shows a conceptus from which a lateral wall has been dissected away in order to reveal the placental arrangement.

Frg. 1. Procyon lotor L.- - the raccoon. Foetus in normal position.

Fig. 2. Lutra canadensis-the Canadian otter. Foetus in normal position.

Fic. 3. Mephitis mephitis-the striped skunk. Foetus removed from allantoic cavity.

Fig. 4. Mephitis macroura-the hooded skunk. Foetus pushed over to one side and antimesometrial region somewhat raised for photography.

Fig. 5. Spilogale putorius-the spotted skunk. Small embryo concealed by membranes. 
PLATE 1
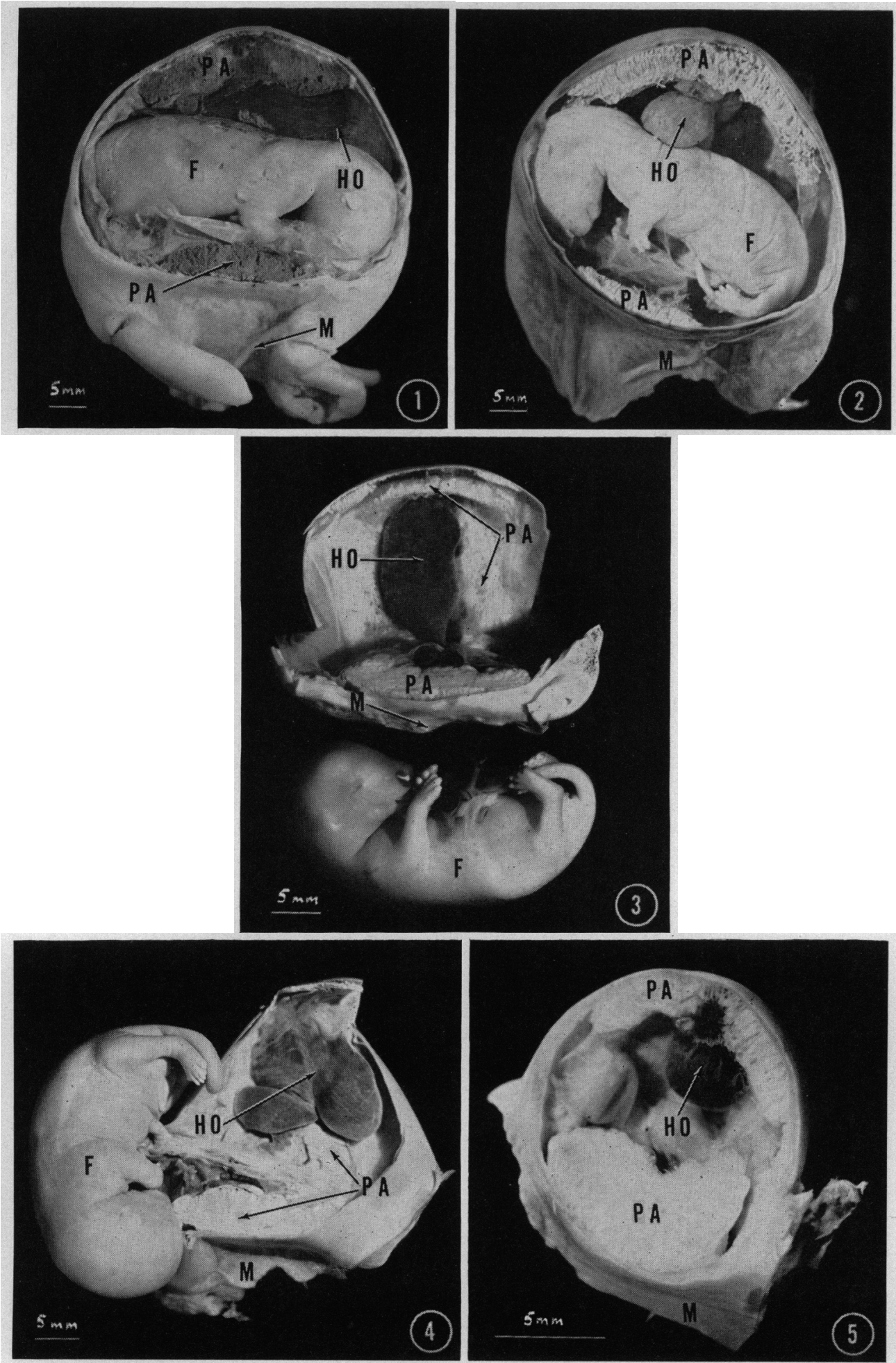

(Facing p. 134) 
the rest of the reproductive tract were lacking. The dissecting away of the greater part of one lateral wall of the conceptus revealed a $45 \mathrm{~mm}$ embryo lying within its amnion inside the allantoic cavity, a complete zonary placenta, and a prominent haemophagous organ emerging from the central, antimesometrial region of the placental annulus. The annulus is considerably wider and deeper at the antimesometrial side than at the mesometrial side.

The haemophagous organ is a multilobular structure consisting of two relatively large lobes and several smaller ones. Each lobe is approximately spherical and at this stage of development the larger ones hang and extend into the allantoic cavity as far as the dorsum of the embryo (Pl. 1, Fig. 2). At their proximal extremities the lobes coalesce to form a common region which is attached to the maternal side of the placenta over a relatively small circular area. Bischoff (1865) described a blood-filled sac-like structure ('blutbeutel') in a similar position in the placenta of the European otter (Lutra vulgaris). This, however, was a single elongated sac and judging from the description he produced as a result of gross observation only, it resembles the haemophagous organ of the raccoon rather than that of the Canadian otter. The haemophagous organ of the latter animal appears to bear a closer resemblance to the central haematoma of the ferret (Strahl \& Ballman, 1915) and the wolverine (Wislocki \& Amoroso, 1956) because of its lobular nature.

\section{Mephitis mephitis-the striped skunk}

The material in this case was obtained from a pregnant striped skunk weighing $1.1 \mathrm{~kg}$, which was captured and killed on 18th April 1962, in Perry County, Pennsylvania. The reproductive tract was removed and fixed in Gendre. Subsequent dissection and examination revealed the presence of $32 \mathrm{~mm}$ embryos in two conceptuses.

The placenta is a zonary one and the annulus is complete, with little or no variation in its width. It is, however, considerably thicker on the mesometrial side than on the antimesometrial side where it becomes extremely thin. This is a reversal of the situation in the raccoon and otter. Its labyrinthine structure is interrupted in a region of a well-marked haemophagous organ. Unlike its condition in the raccoon and otter, this organ does not project far into the allantoic cavity but is a relatively flat spatulate structure applied over a considerable area of attachment to the maternal part of the placental zone. Its midline long axis is parallel to and halfway between the margins of the annulus and is present on one side only between a mesometrial and an antimesometrial point. Its width is approximately one-half that of the zonary girdle. The organ is greatly flattened and extremely shallow at its rounded antimesometrial end and becomes progressively deeper towards its mesometrial limit where it also tapers. At this position a few small lobules of haemophagocytic tissue are present (Pl. 1, Fig. 3).

Mephitis macroura-the hooded skunk

A pregnant hooded skunk was live-trapped at Hacienda Corpus Christi, Chiltepe, Nicaragua, on 18th August 1962. This was later killed and the gravid uterus was removed and fixed in Bouin's solution. Four conceptuses were 
present and subsequent dissection of these revealed the presence of $35 \mathrm{~mm}$ embryos. The placenta is a zonary one, and as in the case of the striped skunk, the annulus is much thicker at the mesometrial than at the antimesometrial side. Once again, the labyrinthine structure is interrupted by the presence of an haemophagous organ of considerable dimensions. This organ differs from that of the striped skunk in its disposition and shape, but resembles it in its flat structure, the fact that it does not project far into the allantoic cavity, and its relatively large area of attachment to the underlying maternal tissue. This attachment area is roughly pear-shaped and its mid-line long axis is parallel to and halfway between the margins of the annulus. The tip of its narrow end is at a point on one side of the annulus midway between the mesometrial and antimesometrial lines and its broad, rounded extremity is at an equivalent position on the opposite side. The haemophagous organ spreads out from this attachment region to overlap in varying degrees the chorio-allantoic covering of the labyrinthine tissue. Its width at the narrowest end is equivalent to about a quarter of the width of the annulus while at its widest part it may extend out and overlap an area equivalent to the entire width of the zonary girdle. Furthermore, at its widest end, beyond its limit of attachment, it bifurcates to form two lobes which may extend well down towards the mesometrial region. It can be noted that the organ is considerably thicker at its widest limit than at the narrow end (Pl. 1, Fig. 4).

Spilogale putorius-the spotted skunk

Observations on the placenta of this species were made on that of a single conceptus containing a $7-\mathrm{mm}$ embryo. This was obtained from the uterus dissected out of a freshly killed animal weighing $322 \mathrm{~g}$ which was live-trapped at Hacienda Las Colinas, Nicaragua, on lst November 1962. The reproductive tract was fixed in Bouin's solution and the placenta and embryo were revealed by the removal of a part of the lateral wall of the conceptus. The zonary placenta is complete and at this early stage the width and thickness of the annulus is such that it occupies the greater part of the inside of the conceptus. It is relatively thick throughout but more so at the mesometrial than at the antimesometrial side. Interruption in the labyrinthine structure is effected by the presence of an haemophagous organ in a central antimesometrial position as in the raccoon and otter. This organ is a spherical sac-like structure whose diameter is approximately twice the diameter of the area of attachment to the underlying maternal tissue (Pl. 1, Fig. 5).

Thus, in representatives of five species of carnivore whose placentae have hitherto not been investigated, the occurrence of a well-defined haemophagous organ can be reported. Except in the cases of the striped and hooded skunks the developmental stages encountered are probably not comparable. However, it seems likely that the gross shape and size of these organs is species specific. On the other hand, histologically their basic pattern in the different species is similar and they consist as in the raccoon, essentially, of a large area of foetal epithelium. This is bathed by maternal blood and the function of the columnar cells, of which it consists, appear to be primarily that of phagocytosis of maternal blood corpuscles. 
Because the specimens present isolated developmental stages, nothing can be said about the ontogenetic origin of these organs. For the same reason it is as yet not possible to discuss changes in gross configuration and size on the one hand, or cytological changes in the haemophagocytic cells on the other hand. In the raccoon (Creed \& Biggers, 1963b) gross, micro-anatomical and cytological changes are considerable and therefore are to be anticipated in the developmental stages of the haemophagous organ in the species under discussion. Whatever changes may be involved, and whatever the gross configuration of the haemophagous organ may be, it seems clear that these species develop extensive areas of foetal epithelia specialized for haemophagocytosis and it must be assumed that such specialization plays an important role in the foetalmaternal relationship.

\section{ACKNOWLEDGMENTS}

This work was supported in part by a generous grant from the National Science Foundation (Grant No. G-17658). We are indebted to the Leptospirosis Unit of the School of Veterinary Medicine, University of Pennsylvania, under the Direction of Dr L. G. Glark for the specimens from Nicaragua, and to the staff of the Pennsylvania Game Commission, Harrisburg for the specimen of Mephitis mephitis. We are also indebted to Mr H. A. Burgess of the Royal Veterinary College for the photography.

\section{REFERENCES}

Bigaers, J. D. \& Creed, R. F. S. (1962) Two morphological types of placentae in the raccoon. Nature, Lond. 194, 103.

Bischofr, T. L. W. (1865) Ueber das Vorkommen eines eigenthumliches Blut and Haematoidin enthaltenden Beutels an der Plazenta der Fischotter (Lutra vulgaris). Sitzungsb. Konig. bay. Akad. Wissensch. Munchen. 1, 214.

CREed, R. F. S. \& BIGGers, J. D. (1963a) Some aspects of placental structure in the raccoon (Procyon lotor L.). J. Anat. $97,475$.

CREED, R. F. S. \& BrgGers, J. D. (1963b) Development of the raccoon placenta. Amer. J. Anat. 113, 417.

Strahl, H. \& Ballman, E. (1915) Embryonalhullen und Plazenta von Putorius furo. Abh. preuss Akad. Wiss. Nr. 4, 3.

WisLockr, G. B. \& Amoroso, E. C. (1956) The placenta of the wolverine (Gulo gulo luscus Linnaeus). Bull. Mus. comp. Zool. Harvard, 114, 91. 